\title{
Facile Preparation of Biocomposite from Prawn Shell Derived Chitosan and Kaolinite-Rich Locally Available Clay
}

\author{
Shanta Biswas, ${ }^{1}$ Taslim U. Rashid, ${ }^{1}$ Abul K. Mallik, ${ }^{1}$ Md. Minhajul Islam, ${ }^{1}$ \\ M. Nuruzzaman Khan, ${ }^{1}$ Papia Haque, ${ }^{1}$ Mala Khan, ${ }^{2}$ and Mohammed Mizanur Rahman ${ }^{1}$ \\ ${ }^{1}$ Department of Applied Chemistry and Chemical Engineering, Faculty of Engineering and Technology, University of Dhaka, \\ Dhaka 1000, Bangladesh \\ ${ }^{2}$ DRiCM, Bangladesh Council of Scientific and Industrial Research (BCSIR), Dr. Qudrat-I-Khuda Road, New Elephant Rd, \\ Dhaka 1205, Bangladesh
}

Correspondence should be addressed to Mohammed Mizanur Rahman; mizanur.rahman@du.ac.bd

Received 26 January 2017; Revised 8 June 2017; Accepted 14 June 2017; Published 18 July 2017

Academic Editor: Hossein Roghani-Mamaqani

Copyright (C) 2017 Shanta Biswas et al. This is an open access article distributed under the Creative Commons Attribution License, which permits unrestricted use, distribution, and reproduction in any medium, provided the original work is properly cited.

\begin{abstract}
A novel composite material was prepared from prawn shell derived chitosan (CHT) and locally available kaolinite-rich modified Bijoypur clay (MC) using a facile technique in which dilute acetic acid was used as a solvent for dissolving chitosan and composite fabrication whereas distilled water was used for preparing the clay dispersion. Bijoypur clay mainly consists of kaolinite clay mineral and it was modified with the dodecyl amine to make it organophilic. Morphology and properties of the composites (different weight ratio of MC and CHT) have been studied and compared with those of pure CHT and MC. Purification and modification of Bijoypur clay were investigated by X-ray diffraction (XRD), X-ray fluorescence (XRF), and Fourier transformed infrared spectroscopy (FTIR) analyses. The fabrication of CHT-MC composites was confirmed by FTIR analysis. Thermogravimetric analysis (TGA) and differential scanning colorimetry (DSC) were used to investigate the thermal stability of the composites. It was observed that dispersed clay improves the thermal stability and enhances the hardness of the matrix systematically with the increase of clay loading. In this study, a better insolubility in both acidic and alkaline media of the composites is also observed compared to pure chitosan.
\end{abstract}

\section{Introduction}

For the past few years, composite materials based on polymer and clay have enticed considerable interest due to its several distinct properties and variegated applications. This is because they can assemble both the physical and chemical properties of inorganic and organic materials. The major portion of the work with polymer/clay composites is based on synthetic polymers compared to natural polymers. The class of synthetic polymers mainly includes thermoplastics, such as nylon, polyethylene, polypropylene, poly(ethylene terephthalate), and thermosets such as epoxy polymers. However, the opportunity to combine natural polymers (biopolymers), such as chitosan, appears as an attractive way to modify some of the properties of this polysaccharide including its solubility and swelling properties, mechanical and thermal behavior, antimicrobial activity, and bioadhesion, when combined with nanometric scale clay $[1,2]$.

Chitin is a naturally abundant polysaccharide which is the supporting material of crustaceans, insects, and so forth and is well known to consist of 2 -acetamido-2-deoxy- $\beta$-Dglucose through a $\beta(1 \rightarrow 4)$ linkage $[3,4]$. Chitosan $(\mathrm{CHT})$, a deacetylated derivative of chitin, has numerous applications in different fields including photography [5], metal capture from waste water $\left(\mathrm{Hg}^{2+}, \mathrm{Cr}^{3+}\right)[6-8]$, and acid dye sorption [9]. The low cost of CHT compared with commercial activated carbon as well as its possible biodegradability made it suitable for removal of heavy metals from industrial effluent [10]. In CHT molecule, the amino sites are the main reactive groups for metals ions, although hydroxyl groups (especially in the $\mathrm{C}_{3}$ position) may contribute to the sorption process [11]. One of the limitations of CHT is that it is soluble in 
dilute aqueous acidic solution $(\mathrm{pH}<6.5)$, which can convert glucosamine units into soluble form $\left(\mathrm{R}^{-\mathrm{NH}_{3}}{ }^{+}\right)$[12] and it also gets precipitated in alkaline solution [13]. Another limitation of CHT as an adsorbent is lower thermal stability. At $500^{\circ} \mathrm{C}$, the weight retention of pure chitosan was found to be $48.5 \%$ [14]. If these properties can be improved by using other materials, then it will be an excellent candidate for various applications like wastewater treatment, packaging purpose, and so on.

Polymer/clay composites are one of the potential candidates as an adsorbent for environmental wastewater treatment due to their structure as well as physical and chemical properties of inorganic and organic materials [2]. However, chitosan/clay composites are interesting because of the easy preparation techniques and inexpensive raw materials and chemical reagents. The most available clay minerals in nature are montmorillonite (MMT), kaolinite (kaolin), and illite. Kaolinite is the major mineral component of kaolin, which usually contains quartz and mica. It also contains small percentages of feldspar, illite, montmorillonite, ilmenite, anastase, haematite, bauxite, zircon, rutile, kyanite, sillimanite, graphite, attapulgite, and halloysite [15, 16]. Bijoypur clay $(187 \mathrm{~km}$ from Dhaka city, located in Netrokona District of Mymensingh Division) is one of the best quality clay types available in Bangladesh. The major phases present in Bijoypur clay are kaolinite, halloysite, and quartz. Although Bijoypur clay has a high content of $\mathrm{SiO}_{2}(70.08 \%)$, it has a substantial amount of $\mathrm{Al}_{2} \mathrm{O}_{3}$ (27.24\%) and fairly low impurity content such as $\mathrm{Fe}_{2} \mathrm{O}_{3}(1.03 \%)$ and $\mathrm{TiO}_{2}(1.65 \%)$ [17]. In many cases, clay materials have been shown to have higher adsorption capacity than that of activated carbon under the same condition because of its high specific surface area, high cation exchange capacity, and positive or negative surface charge against $\mathrm{pH}$ [14]. Considering these unique properties and cost effectiveness locally available kaolinite clay (Bijoypur clay) could be an ideal candidate for composite preparation with CHT. Although chitosan (CHT)/kaolinite clay composites are very attractive, they were not extensively investigated for removal of heavy metals from industrial wastes and there are a relatively small number of scientific publications. Montmorillonite-chitosan bionanocomposites were also found as a potential adsorbent for herbicide clopyralid in aqueous solution and soil/water suspensions and bezactiv Orange V-3R dye $[18,19]$. A nanocomposite based on chitosan and montmorillonite was developed as a carrier to improve oral bioavailability of oxytetracycline [20]. Removal of $\mathrm{Ni}$ (II) and $\mathrm{Cd}(\mathrm{II})$ by adsorption on epichlorohydrin crosslinked chitosan-montmorillonite clay composite beads was observed by Tirtom et al. [21].

The present work describes the fabrication of composite from CHT and locally available Bijoypur clay by a facile technique. Bijoypur clay was found locally and modified with dodecyl amine after acid treatment. The low cost and congenital availability (naturally available) of prawn shell and Bijoypur clay have made this process very convenient in Bangladesh. They have been collected from inside of this country with a minimum price or sometimes for free. Moreover, the least number of chemicals and facilities was needed from CHT extraction to composite fabrication which is also of very low cost. Considering these antecedents, the aim of the present study is to prepare high-performance composites by using chitosan and modified kaolinite clay in various combinations. In the future, the composite will be tested for applying in the variegated field of science starting from waste water treatment to other beneficial purposes by designing the property according to its application.

\section{Materials and Methods}

2.1. Materials. The prawn shells were purchased from a local prawn hatchery of Satkhira District, Khulna Division, Bangladesh. They were washed and grounded in a sample mill (SM-450TR, MRC Scientific Instruments, UK). The source of the clay was Bijoypur of Netrokona District, Dhaka Division, Bangladesh, which was supplied by Bangladesh Insulator and Sanitary Factory Limited (BISF), Dhaka, Bangladesh (screened through 150-mesh screen followed by 200-mesh screen). Sodium hydroxide (Loba Chemie Pvt. Ltd. India), hydrochloric acid (E. Merck, Germany), dodecylamine (Sigma-Aldrich, Sweden), and acetic acid (E. Merck, Germany) were purchased for CHT preparation, clay modification, and composite fabrication. All the chemicals were of analytical grade.

2.2. Extraction of Chitosan from Prawn Shell. Chitosan (CHT) was extracted from waste prawn shell using the modified method of Rashid et al. [22, 23]. The extraction of chitosan from waste prawn shell involves 3 major steps: (a) deproteination, (b) demineralization, and (c) deacetylation. The washed and crushed waste shell was treated with $4 \%$ $(\mathrm{w} / \mathrm{w})$ sodium hydroxide $(\mathrm{NaOH})$ for $3 \mathrm{~h}$ for deproteination. The dried shell was treated with $3 \mathrm{~N} \mathrm{HCl}$ with stirring for $3 \mathrm{~h}$. This step is called demineralization step. After demineralization, this form of prawn shell is pure chitin. The chitin was deacetylated by heating at $80-100^{\circ} \mathrm{C}$ with $50 \% \mathrm{NaOH}(\mathrm{w} / \mathrm{w})$ for $4 \mathrm{~h}$ to have chitosan. The degree of deacetylation (DD) of chitosan was found to be $77.2 \%$ and the molecular weight of $1138356 \mathrm{Da}$ was determined from its viscosity.

2.3. Purification and Modification of Clay. The raw clay (RC) was purified by treating with hydrochloric acid. After acid treatment, the purified clay was modified with the dodecyl amine to induce its organophilic character according to the previously reported method [24]. After modification, the clay was washed with hot distilled water to become neutral and dried to have modified clay (MC).

2.4. Preparation of Chitosan/Modified Clay Composite. The composite was prepared by a modified method developed by Wang et al. [25]. In a typical procedure, $1 \%$ chitosan solution and $1 \%$ modified clay dispersion (dispersed by simple stirring by using a magnetic stirrer) were mixed in different weight ratio and stirred at $60^{\circ} \mathrm{C}$. The modified clay amount varied from $0.33 \mathrm{gm}$ to $1.5 \mathrm{gm}$. The CHT-MC mixture was cast on a Petri dish and placed at $60^{\circ} \mathrm{C}$ for $48 \mathrm{~h}$ in an oven. The dry film still contained a small quantity of the solvent, which formed chitosonium acetate. So, after drying the films were soaked in 
TABLE 1: Different weight ratio of chitosan (CHT) and modified Bijoypur clay (MC) in different composites.

\begin{tabular}{lccc}
\hline Composites & Nomenclature & CHT (\% by wt.) & MC (\% by wt.) \\
\hline CHT-MC $(2: 1)$ & SB-1 & 1.50 & 0.33 \\
CHT-MC $(1.2: 1)$ & SB-2 & 0.54 & 0.45 \\
CHT-MC $(1: 1)$ & SB-3 & 0.50 & 0.50 \\
CHT-MC $(1: 1.6)$ & SB-4 & 0.38 & 0.61 \\
CHT-MC $(1: 2)$ & SB-5 & 0.33 & 1.50 \\
\hline
\end{tabular}

$1 \mathrm{M}$ aqueous $\mathrm{NaOH}$ solution to neutralize the acid followed by rinsing with distilled water to neutralize and then dried at $60^{\circ} \mathrm{C}$ for $24 \mathrm{~h}$. The different weight ratio of $\mathrm{CHT}$ and $\mathrm{MC}$ used for composite fabrication is listed in Table 1.

\subsection{Characterization of the Raw Materials and Composites}

2.5.1. Fourier Transform Infrared (FTIR) Spectroscopy Anal$y$ sis. Fourier transform infrared (FTIR) spectra (transmission) of CHT, MC, and composites were observed on a FTIR 8400 S spectrophotometer (Shimadzu Corporation, Japan).

2.5.2. Thermal Analysis. To analyze the thermal behavior, thermogravimetric analysis (TGA) of CHT, MC, and composites was performed in aluminum cell under nitrogen flow from room temperature to $600^{\circ} \mathrm{C}$ at a rate of $20^{\circ} \mathrm{C} / \mathrm{min}$ with a TGA-50 instrument (Shimadzu Corporation, Japan). The weights of samples varied from 2 to $9 \mathrm{mg}$. A differential scanning calorimeter (DSC-60, Shimadzu Corp., Japan) was used to determine the glass transition and/or decomposition temperature of the composite materials.

2.5.3. Scanning Electron Microscopy (SEM). A high-performance, low-cost, scanning electron microscope (SEM) (JSM6490 ) with a high resolution of $3.0 \mathrm{~nm}$ at $30 \mathrm{kV}$ was used to determine the surface morphological characteristics of the composites.

2.5.4. X-Ray Diffraction (XRD) Analysis. For the analysis of minerals present in raw clay and purified clay, XRD analysis was carried out by X-ray diffractometer (model BRUKER AXS Diffractometer D8, Germany). The monochromatic Cu $\alpha_{1}$ line is isolated by various monochromator in the $\mathrm{X}$-ray tube and used for the analysis. The composites were also analyzed by XRD data.

2.5.5. X-Ray Fluorescence (XRF) Analysis. For the elemental analysis of raw clay, purified clay and MC XRF spectrometer were used (Thermoscientific ARL Quant'x EDXRF Analyzer). Rapid elemental analysis from fluorine (F) to uranium (U) was done in XRF. The sensitivity was from $<1 \mathrm{ppm}$ up to $100 \%$ with adjustable X-ray beam size from 1 to $15 \mathrm{~mm}$. It was found with electrically cooled $\mathrm{Si}(\mathrm{Li})$ detector.

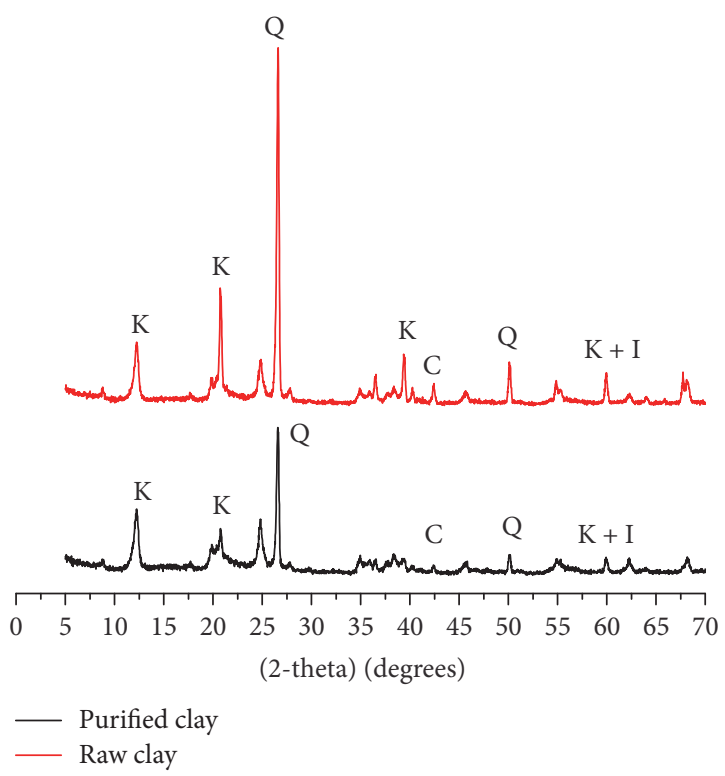

FIGURE 1: XRD analysis of raw clay and purified clay (K: kaolinite, I: illite, C: calcite, and Q: quartz).

\section{Results and Discussion}

3.1. Purification of Bijoypur Clay. The quantitative analysis by X-ray diffraction (XRD) of Bijoypur clay before and after acid treatment showed that it is a mixture mainly of kaolinite $\left(\mathrm{Al}_{2} \mathrm{O}_{3} \cdot 2 \mathrm{SiO}_{2} \cdot 2 \mathrm{H}_{2} \mathrm{O}\right)$ and illite; however, the major phase is kaolinite.

Figure 1 of raw clay showed well-defined reflections at $2 \theta$ value of $12^{\circ}$ and $25^{\circ}$, typical characteristic peaks of kaolinite. The peaks at $12.12^{\circ}$ and $20.72^{\circ}$ represent the Si-O-Si crystalline layers of the clay [26]. The presence of quartz impurities was also detected at $25.52^{\circ}$ which was confirmed from the results obtained in the literature [27]. After treatment with $\mathrm{HCl}$, the peak intensity of quartz and other minerals in the raw clay was significantly decreased due to the structural disorder that occurred owing to the acid treatment. The narrowing of the peak shape may be due to the decrease of the mean lattice strain or the increase of crystallite size [22]. The comparison of the XRD data of raw clay and purified clay demonstrated that $\mathrm{HCl}$ treatment did not have a significant loss in the crystallinity of the clay materials. In addition, the quartz impurities cannot be completely removed by the acid treatment. However, the percentage of quartz could be reduced to almost 55\% in the purified clay.

3.2. Modification of Bijoypur Clay. Figure 2 showed the FTIR spectra of raw clay and the characteristic peaks were found at $3459 \mathrm{~cm}^{-1}, 1633 \mathrm{~cm}^{-1}, 912 \mathrm{~cm}^{-1}$ (Al-OH bonds), and $795 \mathrm{~cm}^{-1}$. Stretching of $-\mathrm{OH}$ groups coordinated to the octahedral cations can be found at $3696,3668,3653$, and $3619 \mathrm{~cm}^{-1}$. The most important mineral peaks both in raw clay and in modified clay were observed at 1114, 1030, and $1006 \mathrm{~cm}^{-1}$, respectively, due to $\mathrm{Si}-\mathrm{O}$ stretching. After modification with dodecylamine, it exhibited additional peaks at $2910 \mathrm{~cm}^{-1}\left(-\mathrm{CH}_{3}\right.$ stretching $)$ and $2841 \mathrm{~cm}^{-1}\left(-\mathrm{CH}_{2}\right.$ stretching 


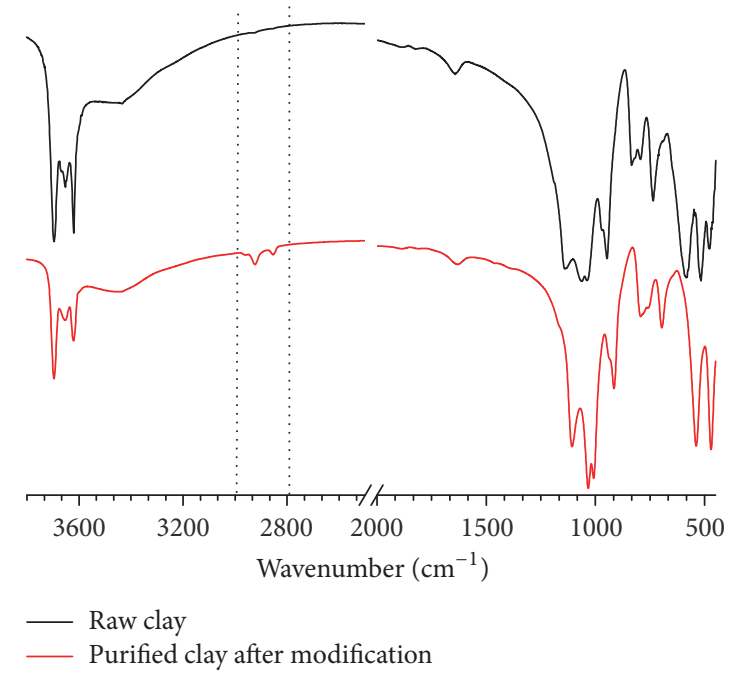

FIGURE 2: FTIR spectra of raw clay and modified clay.

TABLE 2: Elemental analysis of raw clay, purified clay, and modified clay.

\begin{tabular}{lccc}
\hline Elements & Raw clay (\%) & $\begin{array}{c}\text { Purified clay } \\
(\%)\end{array}$ & $\begin{array}{c}\text { Modified clay } \\
(\mathrm{MC})(\%)\end{array}$ \\
\hline Silicon $(\mathrm{Si})$ & 69.9 & 76.4 & 77.0 \\
Aluminum (Al) & 14.5 & 10.8 & 10.8 \\
Potassium (K) & 3.72 & 4.04 & 4.16 \\
Titanium (Ti) & 4.03 & 3.77 & 3.65 \\
Iron (Fe) & 5.38 & 3.01 & 2.87 \\
Calcium (Ca) & 0.56 & 0.29 & 0.22 \\
Others & 2.05 & 1.74 & 1.72 \\
\hline
\end{tabular}

vibrations), respectively, which indicates that the alkyl ammonium chains have been intercalated into the galleries of clay by a cation exchange reaction and a successful modification of Bijoypur clay was achieved.

3.3. XRF Analysis of Raw Clay, Purified Clay, and Modified Clay (MC). The elemental analysis by XRF showed that the percentages of silicon ( $\mathrm{Si}$ ) increased (from 69.8 to $75.4 \%$ ) whereas aluminum $(\mathrm{Al})$ decreased from 14.5 to $10.8 \%$ compared to raw clay to purified clay (as shown in Table 2). The other elements like potassium $(\mathrm{K})$, iron $(\mathrm{Fe})$, calcium $(\mathrm{Ca})$, and titanium $(\mathrm{Ti})$ were identified in raw, purified, and modified clay. $\mathrm{K}, \mathrm{Ti}, \mathrm{Ca}$, and $\mathrm{F}$ were found as free oxide form (i.e., $\mathrm{K}_{2} \mathrm{O}$, $\mathrm{TiO}_{2}, \mathrm{CaO}$, and $\mathrm{Fe}_{2} \mathrm{O}_{3}$ ); however $\mathrm{Si}$ and $\mathrm{Al}$ shaped the major phase of kaolinite as $\mathrm{SiO}_{2}$ and $\mathrm{Al}_{2} \mathrm{O}_{3}$, respectively. The acid treatment induced a significant decrease of $\mathrm{Fe}_{2} \mathrm{O}_{3}$ content in purified clay [27].

The further significant decrease of iron content in modified clay resulted due to the presence of strong acid in the modification process. The oxide form of iron was removed as water soluble chloride form $\left(\mathrm{FeCl}_{3}\right)$ by the addition of acid.

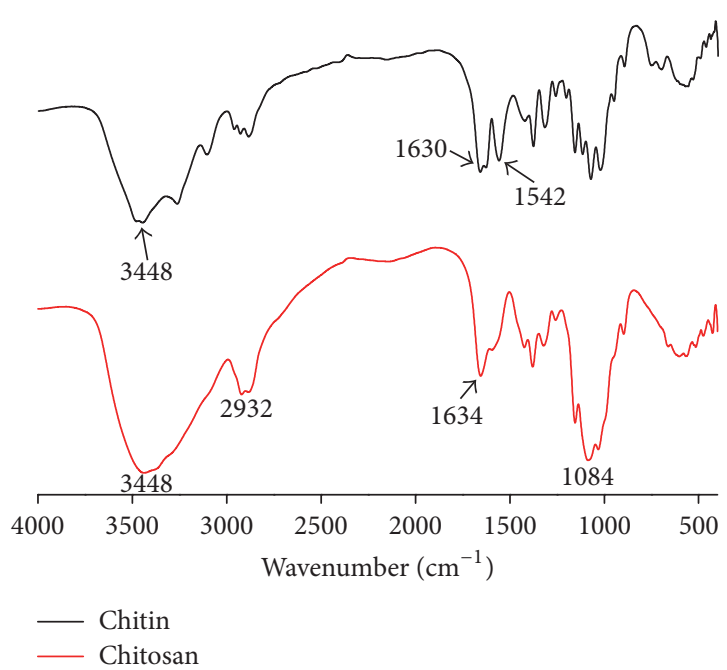

FIGURE 3: FTIR spectra of chitin and chitosan.

3.4. FTIR Analysis of CHT-MC Composites. The FTIR spectra of chitin and chitosan are shown in Figure 3. In the case of chitin, the main absorption bands were assigned at $3448 \mathrm{~cm}^{-1}$ (O-H stretching vibrations overlapped with the N-H stretching vibrations), $2932 \mathrm{~cm}^{-1}$ (C-H stretching vibration of $\mathrm{CH}_{2}$ symmetry), $1630 \mathrm{~cm}^{-1}$ ( $\mathrm{C}=\mathrm{O}$ stretching vibrations of amide bonds), $1542 \mathrm{~cm}^{-1}$ (N-H bending vibrations of amide bonds which were overlapped with $\mathrm{C}=\mathrm{O}$ stretching vibrations of amide bonds), $1084 \mathrm{~cm}^{-1}\left(\mathrm{C}_{6}-\mathrm{O}\right.$ stretching vibrations overlapped with $\mathrm{C}=\mathrm{O}$ stretching vibrations), $1006 \mathrm{~cm}^{-1}$ (C-O-C bridge stretching vibrations), $1369 \mathrm{~cm}^{-1}$ (asymmetrical $\mathrm{C}-\mathrm{H}$ bending vibrations of the $\mathrm{CH}_{2}$ group), $1127 \mathrm{~cm}^{-1}\left(\mathrm{C}_{3}-\mathrm{O}\right.$ stretching vibration), and finally $886 \mathrm{~cm}^{-1}$ due to the $\mathrm{C}-\mathrm{H}$ deformation vibrations of the $\beta$-glycosidic bond. On the other hand, in case of chitosan, the main absorption bands were at $3448 \mathrm{~cm}^{-1}(\mathrm{O}-\mathrm{H}$ stretching overlapping the $\mathrm{N}-\mathrm{H}$ stretching of primary amine), $2927 \mathrm{~cm}^{-1}$ (C-H stretching vibration of $\mathrm{CH}_{2}$ symmetry), $1634 \mathrm{~cm}^{-1}$ ( $\mathrm{C}=\mathrm{O}$ stretching of amide bonds), $1084 \mathrm{~cm}^{-1}\left(\mathrm{C}_{6}-\mathrm{O}\right.$ stretching overlapped with $\mathrm{C}=\mathrm{O}$ stretching), $1006 \mathrm{~cm}^{-1}$ (C-O-C bridge stretching), $1369 \mathrm{~cm}^{-1}$ (asymmetrical $\mathrm{C}-\mathrm{H}$ bending of the $\mathrm{CH}_{2}$ group), and $1127 \mathrm{~cm}^{-1}\left(\mathrm{C}_{3}-\mathrm{O}\right.$ stretching). The significant differences observed in FTIR spectra of chitin and chitosan were at region 3350-3500 $\mathrm{cm}^{-1}$. Broader peak appeared for chitosan compared to chitin peak indicating the increased deacetylated part in chitosan because of that specific region which corresponded to the $\mathrm{O}-\mathrm{H}$ stretching overlapping the $\mathrm{N}-\mathrm{H}$ stretching. The peak at $1634 \mathrm{~cm}^{-1}$ distinguished the chitin from chitosan in terms of intensity. The higher the peak area in chitin, the more acetylated part in chitin with respect to chitosan $[28,29]$.

In case of MC (as observed in Figure 2), the characteristic band for $-\mathrm{OH}$ stretching was found at $3459 \mathrm{~cm}^{-1}$, bending due to presence of water was observed at $1633 \mathrm{~cm}^{-1}$, the most important mineral bands were observed at 1114, 1030, and $1006 \mathrm{~cm}^{-1}$ due to $\mathrm{Si}-\mathrm{O}$ stretching vibration modes, the peak was found due to the presence of Al-OH bonds at $912 \mathrm{~cm}^{-1}$, a 


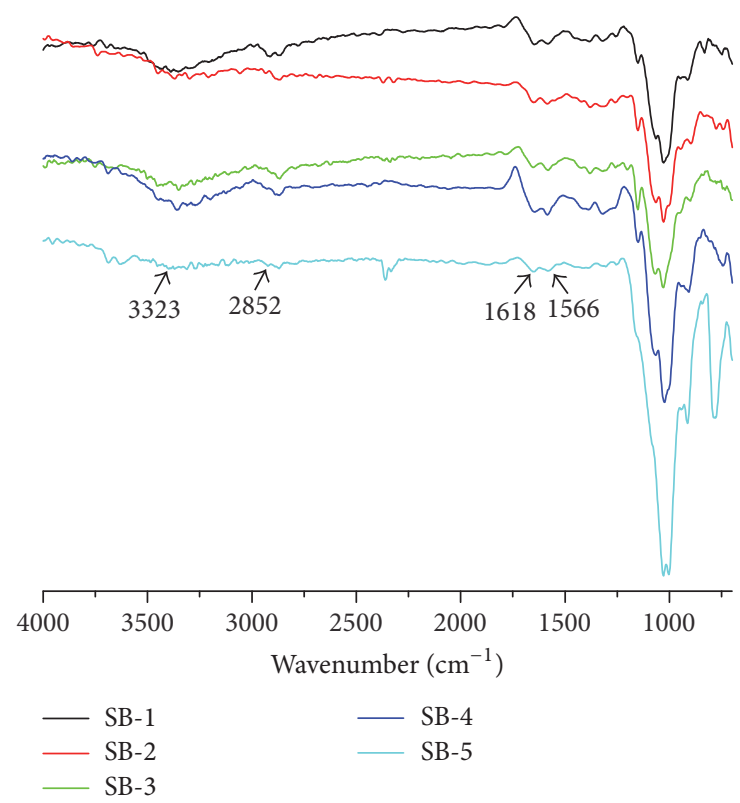

FIGURE 4: FTIR spectra of composites.

strong band at $795 \mathrm{~cm}^{-1}$ was observed because of free silica and/or quartz admixtures, and bands at $2910 \mathrm{~cm}^{-1}\left(-\mathrm{CH}_{2}\right.$ stretching) and $2841 \mathrm{~cm}^{-1}$ (- $\mathrm{CH}_{2}$ stretching vibrations) indicated the intercalation of alkyl ammonium chains into the galleries of Bijoypur clay (kaolinite) (Figure 2). When the protons in chitosan are hydrogen-bonded to the oxygen species of $\mathrm{Si}-\mathrm{O}$ and $\mathrm{Al}-\mathrm{O}$ segment, $\mathrm{Si}-\mathrm{O}$ and $\mathrm{Al}-\mathrm{O}$ bonds would be weakened and the tetrahedral symmetry of these moieties will be distorted. On the other hand, FTIR spectra showed that the CHT-MC composites exhibited all resolved N-H, O$\mathrm{H}$, and $\mathrm{C}-\mathrm{H}$ bands when the composites were formed. The composites (SB-1, SB-2, SB-3, SB-4, and SB-5) showed three stretching vibration regions: $\mathrm{N}-\mathrm{H}$ and $\mathrm{O}-\mathrm{H}$ from chitosan and $\mathrm{O}-\mathrm{H}, \mathrm{Si}-\mathrm{O}$, and $\mathrm{Al}-\mathrm{OH}$ from clay. This resulted in the change of the IR band positions as well as the reduction of intensities of the bands. It can clearly be seen that the FTIR spectra of CHT-MC composites exhibit the presence of characteristic absorptions due to the organic and inorganic groups [26]. The FTIR spectra of composites in Figure 4 showed the bands due to $-\mathrm{NH}_{2}$ group at $1558 \mathrm{~cm}^{-1}, 1550 \mathrm{~cm}^{-1}, 1566 \mathrm{~cm}^{-1}$, $1566 \mathrm{~cm}^{-1}$, and $1550 \mathrm{~cm}^{-1}$ for SB-1, SB-2, SB-3, SB-4, and SB5 , respectively.

Additionally, the CHT-MC composites showed bands at $1618 \mathrm{~cm}^{-1}$ (N-H bending) and $1566 \mathrm{~cm}^{-1}$ (N-H bending) and also absorbencies due to $\mathrm{O}-\mathrm{H}$ stretching at $3323 \mathrm{~cm}^{-1}$. There was a shifting of the band at $2881 \mathrm{~cm}^{-1}$ which showed the stretching vibration of $-\mathrm{CH}_{2}$ group present in $\mathrm{MC}$. In $\mathrm{MC}$ sharp band was observed at $3614 \mathrm{~cm}^{-1}$ and $3690 \mathrm{~cm}^{-1}$ that indicated the presence of free - $\mathrm{OH}$ group in the clay (Figure 2), while in composite the peak was found to be in a shifted position at $3315 \mathrm{~cm}^{-1}$ and became broad as well. That shifting and broadening indicated the formation of $\mathrm{H}$ bond by $-\mathrm{OH}$ group of the clay. Al-Al-OH vibrations at $914 \mathrm{~cm}^{-1}, \mathrm{Al}-\mathrm{Mg}-\mathrm{OH}$ vibration at $792 \mathrm{~cm}^{-1}, \mathrm{Si}-\mathrm{O}-\mathrm{Si}$ bending

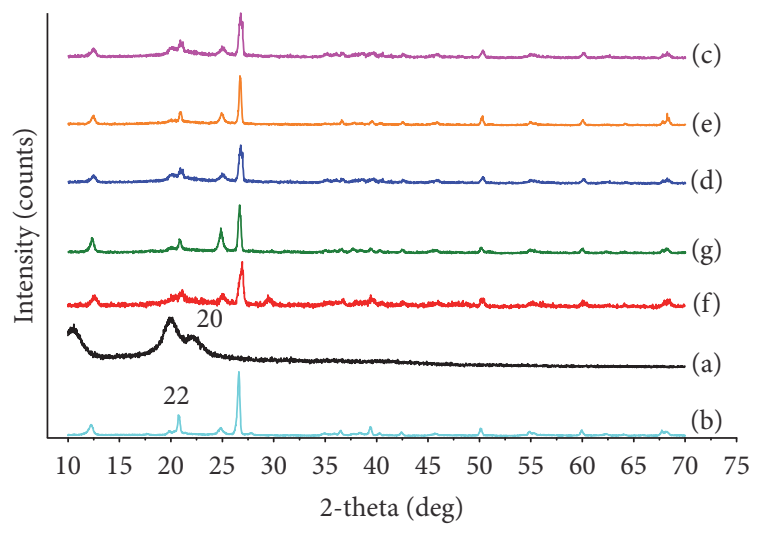

Figure 5: XRD of CHT-MC composites ((a) CHT, (b) RC, (c) SB-1, (d) SB-2, (e) SB-4, (f) SB-3, and (g) SB-5).

at $702 \mathrm{~cm}^{-1}$, and $\mathrm{Si}-\mathrm{O}-\mathrm{Si}$ stretching at $1028 \mathrm{~cm}^{-1}$ confirmed the presence of clay. The spectra SB-1, SB-2, SB-4, and SB-5 also contained almost all the characteristic bands of all components. Finally, shifting of the band around $1590 \mathrm{~cm}^{-1}$ of chitosan to lower frequency around $1560 \mathrm{~cm}^{-1}$ in the composite indicates the possible interaction established between chitosan and the clay mineral. All these spectral data revealed that the chitosan molecules and clay particles may interact on the surface of each other.

3.5. XRD Analysis of CHT-MC Composites. The standard characteristic peaks of kaolinite mineral in raw clay were observed at $12^{\circ}, 20^{\circ}, 27^{\circ}$, and $40^{\circ}$ [26]. The basal peaks of kaolinite mineral in raw clay which are found in this case (Figure 5) are $12^{\circ}, 22^{\circ}, 39^{\circ}$, and $51^{\circ}$. The XRD pattern of CHT shows the characteristic crystalline peaks at around 2 theta $=$ $10^{\circ}, 20^{\circ}$, and $25^{\circ}$ [30]. Now, comparing the XRD pattern of the composites (SB-1 to SB-5), it was observed that the characteristic peak of kaolinite at $40^{\circ}$ has disappeared in all of the composites after the clay was incorporated in the CHT. The peak of clay at $22^{\circ}$ was broadened and also shifted very slightly to some lower angle point. Moreover, this broadening of the peak of the composite at $20^{\circ}$ was observed more intensely due to the presence of the $\mathrm{CHT}$ in the composite, which also gives a characteristic peak at $20^{\circ}$.

This kind of phenomena was observed in montmorillonite clay while combining with chitosan forming a nanocomposite and it was concluded that the combination of the materials is either intercalated or exfoliated [25]. However, it is very difficult to conclude whether it is exfoliated or intercalated without the TEM images. Since one chitosan unit possesses one amino and two hydroxyl functional groups, these functional groups can form hydrogen bonds with the silicate hydroxylated edge groups in the clay, which is previously proved in the FTIR analysis of the composite. This kind of interaction is believed to be the main driving force for the assembly of kaolinite clay in the chitosan matrix to form a flocculated structure. Moreover, the highly crystalline structure of clay and semicrystalline nature of chitosan (peak at $10^{\circ}$ and $20^{\circ}$ ) are absent in the XRD data of the composites; rather 


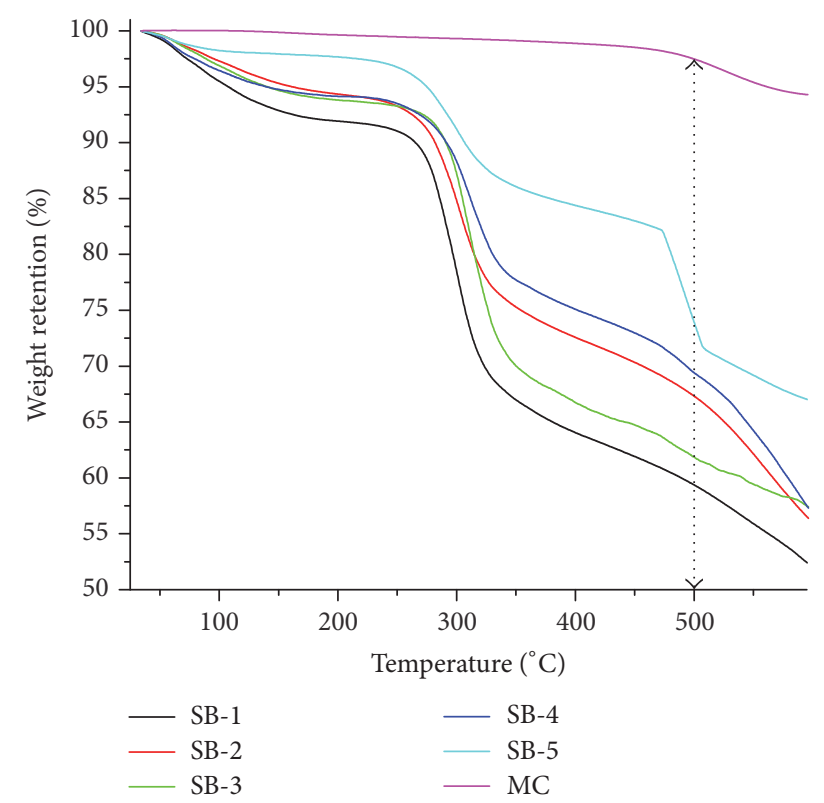

FIGURE 6: TGA curves of composites.

they give a partially amorphous structure, which indicates a pretty good dispersion of the CHT and clay.

3.6. Thermal Stability of CHT-MC Composites. The thermal stability of the MC and its composites was investigated by TGA under nitrogen flows. Under nitrogen flow, a nonoxidative degradation occurred. There were two steps of degradation for the composites; first range $\left(50-200^{\circ} \mathrm{C}\right)$ was associated with the loss of water which was about 5-9 wt.\%, whereas the second range $\left(200-350^{\circ} \mathrm{C}\right)$ corresponded to the degradation and deacetylation of chitosan [31, 32]. Composite SB-1 decomposed faster than any other composite and SB-5 showed the highest resistance to temperature increase (as shown in Figure 6).

Clay increases thermal stability of CHT-MC composites; at higher loads of clay the decomposition temperature increased. This is the result of formation of parallel monolayers of clay that can form strong electrostatic interactions with chitosan. The higher loads of clay decrease the regularity of the structure and thus decrease the strength of electrostatic interactions [2]. However, the various physiochemical changes and the weight loss at $600^{\circ} \mathrm{C}$ due to heat treatment are shown in Table 4.

At $256-340^{\circ} \mathrm{C}$, sudden drop in temperature was observed due to the decomposition of organic and other volatile matters present in the composites. Concerning the residue at $600^{\circ} \mathrm{C}$, in the case of SB-5 which contained the highest amount of clay, the weight loss was about $28 \%$, indicating that the complete organic phase was decomposed. In case of the lowest amount of clay content in SB-1, the weight loss was approximately $42 \%$. When loads of clay were lowered, parts of chitosan tend to char during degradation. These composites were stable up to $200^{\circ} \mathrm{C}$ which indicated a good sign for using in the discharge point of the effluent from the factory, where the effluent temperature existed to be found
TABLE 3: The decomposition temperature of the composites.

\begin{tabular}{lc}
\hline Composite & Decomposition temperature $\left({ }^{\circ} \mathrm{C}\right)$ \\
\hline SB-1 & 301.004 \\
SB-2 & 302.14 \\
SB-3 & 302.21 \\
SB-4 & 307.80 \\
SB-5 & 304.15 \\
\hline
\end{tabular}



FIGURE 7: DSC curves of composites.

at high temperature $\left(100\right.$ to $\left.150^{\circ} \mathrm{C}\right)$. At the decomposition temperature, the composites showed higher thermal stability compared to those of the pure CHT. The DSC thermogram of composites within the temperature range of 50 to $400^{\circ} \mathrm{C}$ at a heating rate of $10^{\circ} \mathrm{C} / \mathrm{min}$ is shown in Figure 7 . A very slight endothermic peak at temperature $40-45^{\circ} \mathrm{C}$ indicated the solvent evaporation that was present in very small quantity $[29,33]$. The sharp exothermic peak was observed at $302-307^{\circ} \mathrm{C}$ for different composite as shown in Table 3.

However, there are several reasons behind the variable glass transition temperature of chitosan, which depends on some very interesting issues. Firstly, being a natural polymer, some properties like crystallinity, molecular weight, and deacetylation degree can affect the glass transition temperature of chitosan. Secondly, a wide variation in glass transition temperature may be observed due to the source and/or method of extraction. Generally the minimum and maximum glass transition temperature of chitosan are $-23^{\circ} \mathrm{C}$ and $203^{\circ} \mathrm{C}$, respectively $[31,32]$, and the decomposition temperature of chitosan was found $295^{\circ} \mathrm{C}$ [34].

3.7. Morphological Characterization of CHT-MC Composites. SEM images of composites (SB-1 and SB-5) are shown in Figure 8. The influence of clay concentration on chitosan depends on the type of composites formed (tactoids, intercalation, and exfoliation). The major two nanoscale composites are intercalation and exfoliation. The formation of these two ideal state nanocomposites depends on the types and the amounts of clay used [29]. Figure 8 indicates that the clay particles were dispersed throughout the chitosan matrix. However, the micrographs revealed that the SB-1 possessed a more uniform and smooth surface than SB-5 [33]. From visual analysis of SEM images, it can be seen that with the increase in 
TABLE 4: Temperature profile and weight variation of the materials.

\begin{tabular}{|c|c|c|c|c|}
\hline \multirow{2}{*}{ Material } & \multicolumn{3}{|c|}{ Temperature $\left({ }^{\circ} \mathrm{C}\right)$} & \multirow{2}{*}{$\begin{array}{c}\text { (Weight } \%) \\
\text { Weight loss at } 600^{\circ} \mathrm{C}\end{array}$} \\
\hline & Moisture removal & Volatile and organic matter removal & Degradation temperature & \\
\hline $\mathrm{CHT}$ & $50-200$ & - & $200-350$ & 55 \\
\hline $\mathrm{MC}$ & Up to 100 & - & Not mentionable & 6 \\
\hline SB-1 & $50-150$ & $256-360$ & Above 300 & 53 \\
\hline SB-2 & $50-150$ & $256-360$ & Above 350 & 50 \\
\hline SB-3 & $50-150$ & $256-360$ & Above 300 & 45 \\
\hline SB-4 & $50-150$ & $256-360$ & Above 350 & 44 \\
\hline SB-5 & Below 100 & $240-300$ & $\begin{array}{c}\text { Two steps: } 450-500 \\
500-600\end{array}$ & 37 \\
\hline
\end{tabular}

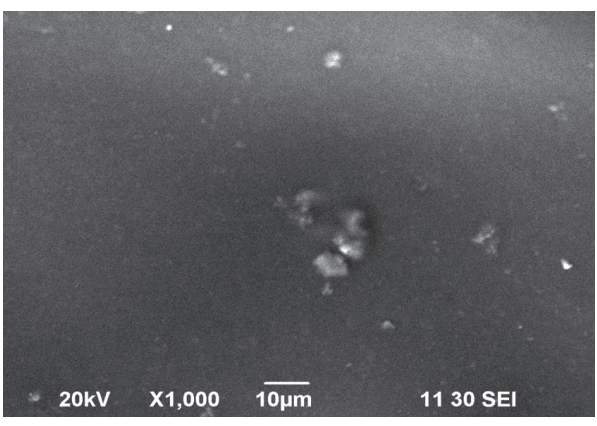

(a)

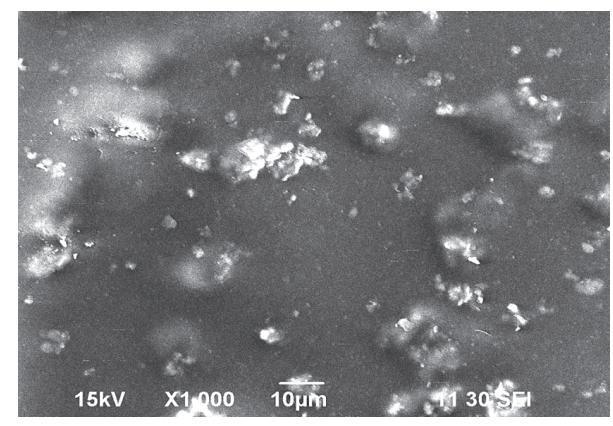

(b)

FIGURE 8: SEM images of the surface of CHT-MC composites; (a) SB-1 and (b) SB-5.

the amount of clay in the composite the surface becomes very rough. As the SB-5 consisted of the highest amount of clay, its surface became rougher compared to SB-1. Nevertheless, it is necessary to continue working in this aspect, by means of applying other techniques such as AFM (Atomic Force Microscopy), which could allow the complete identification of intercalation or exfoliation of clay as well as determination of the degree of interaction between the particles of clay and chitosan [33].

\section{Conclusion}

The results described above can be concluded as follows:

(i) Bijoypur clay is rich in kaolinite and acid treatment can keep the crystalline structure of clay.

(ii) The composite showed higher thermal stability than chitosan which is beneficiary for the application of chitosan/clay composite in different purposes.

(iii) Pure chitosan gets dissolved in acidic media [12] and forms precipitate in alkaline media [13]. This is sometimes a barrier for using this material in various useful purposes like as an adsorbent, as packaging material, and so on. But this composite improved the solubility characteristics in both acidic and basic media and it was found that the composites became undissolved in acidic media ( $\mathrm{pH} 4.9$ ) and did not form the precipitate at higher $\mathrm{pH}(\mathrm{pH} 10)$. This kind of stability intensifies the use of this composite in various applications in the future, more importantly in adsorption purpose when the solution is too acidic or too basic.

\section{Conflicts of Interest}

The authors declare that they have no conflicts of interest.

\section{Acknowledgments}

Mohammed Mizanur Rahman highly acknowledges the Organization for the Prohibition of Chemical Weapons (OPCW) for their research grant (Project Account no. L/ICA/ICB/194479/14) to carry out the research.

\section{References}

[1] S. Pandey and S. B. Mishra, "Organic-inorganic hybrid of chitosan/organoclay bionanocomposites for hexavalent chromium uptake," Journal of Colloid and Interface Science, vol. 361, no. 2, pp. 509-520, 2011.

[2] Y.-S. Han, S.-H. Lee, K. H. Choi, and I. Park, "Preparation and characterization of chitosan-clay nanocomposites with antimicrobial activity," Journal of Physics and Chemistry of Solids, vol. 71, no. 4, pp. 464-467, 2010.

[3] R. A. A. Muzzarelli, Natural Chelating Polymers; Alginic Acid, Chitin and Chitosan, Pergamon Press, 1973.

[4] J. Zikakis, Chitin, Chitosan, and Related Enzymes, Elsevier, 2012. 
[5] R. A. A. Muzzarelli, "Human enzymatic activities related to the therapeutic administration of chitin derivatives," Cellular and Molecular Life Sciences, vol. 53, no. 2, pp. 131-140, 1997.

[6] K. R. Nair and P. Madhavan, "Chitosan for removal of mercury from water," 1984.

[7] R. Maruca, B. J. Suder, and J. P. Wightman, "Interaction of heavy metals with chitin and chitosan. III. Chromium," Journal of Applied Polymer Science, vol. 27, no. 12, pp. 4827-4837, 1982.

[8] C. Peniche-Covas, L. W. Alvarez, and W. Argüelles-Monal, “The adsorption of mercuric ions by chitosan," Journal of Applied Polymer Science, vol. 46, no. 7, pp. 1147-1150, 1992.

[9] W. H. Cheung, Y. S. Szeto, and G. McKay, "Intraparticle diffusion processes during acid dye adsorption onto chitosan," Bioresource Technology, vol. 98, no. 15, pp. 2897-2904, 2007.

[10] A. J. Varma, S. V. Deshpande, and J. F. Kennedy, "Metal complexation by chitosan and its derivatives: a review," Carbohydrate Polymers, vol. 55, no. 1, pp. 77-93, 2004.

[11] S. Babel and T. A. Kurniawan, "Low-cost adsorbents for heavy metals uptake from contaminated water: a review," Journal of Hazardous Materials, vol. 97, no. 1-3, pp. 219-243, 2003.

[12] M. N. V. R. Kumar, R. A. A. Muzzarelli, C. Muzzarelli, H. Sashiwa, and A. J. Domb, "Chitosan chemistry and pharmaceutical perspectives," Chemical Reviews, vol. 104, no. 12, pp. 60176084, 2004.

[13] C. Q. Qin, H. R. Li, Q. Xiao, Y. Liu, J. C. Zhu, and Y. M. $\mathrm{Du}$, "Water-solubility of chitosan and its antimicrobial activity," Carbohydrate Polymers, vol. 63, no. 3, pp. 367-374, 2006.

[14] C. G. T. Neto, J. A. Giacometti, A. E. Job, F. C. Ferreira, J. L. C. Fonseca, and M. R. Pereira, "Thermal analysis of chitosan based networks," Carbohydrate Polymers, vol. 62, no. 2, pp. 97103, 2005.

[15] C. Belver, M. A. Bañares Muñoz, and M. A. Vicente, "Chemical activation of a kaolinite under acid and alkaline conditions," Chemistry of Materials, vol. 14, no. 5, pp. 2033-2043, 2002.

[16] G. Varga, "The structure of kaolinite and metakaolinite," Epitoanyag - Journal of Silicate Based and Composite Materials, vol. 59, no. 1, pp. 6-9, 2007.

[17] A. Mousharraf, M. S. Hossain, and M. F. Islam, "Potential of Locally Available Clay as Raw Material for Traditional-Ceramic Manufacturing Industries," Journal of Chemical Engineering, vol. 26, no. 1, 2012.

[18] R. Celis, M. A. Adelino, M. C. Hermosín, and J. Cornejo, "Montmorillonite-chitosan bionanocomposites as adsorbents of the herbicide clopyralid in aqueous solution and soil/water suspensions," Journal of Hazardous Materials, vol. 209-210, pp. 67-76, 2012.

[19] A. R. Nesic, S. J. Velickovic, and D. G. Antonovic, "Characterization of chitosan/montmorillonite membranes as adsorbents for Bezactiv Orange V-3R dye," Journal of Hazardous Materials, vol. 209-210, pp. 256-263, 2012.

[20] I. Salcedo, G. Sandri, C. Aguzzi et al., "Intestinal permeability of oxytetracycline from chitosan-montmorillonite nanocomposites," Colloids and Surfaces B: Biointerfaces, vol. 117, pp. 441-448, 2014.

[21] V. N. Tirtom, A. Dinçer, S. Becerik, T. Aydemir, and A. Çelik, "Comparative adsorption of $\mathrm{Ni}(\mathrm{II})$ and $\mathrm{Cd}(\mathrm{II})$ ions on epichlorohydrin crosslinked chitosan-clay composite beads in aqueous solution," Chemical Engineering Journal, vol. 197, pp. 379-386, 2012.

[22] T. U. Rashid, M. M. Rahman, S. Kabir, S. M. Shamsuddin, and M. A. Khan, "A new approach for the preparation of chitosan from $\gamma$-irradiation of prawn shell: effects of radiation on the characteristics of chitosan," Polymer International, vol. 61, no. 8, pp. 1302-1308, 2012.

[23] M. M. Rahman, S. Kabir, T. U. Rashid et al., "Effect of $\gamma$ irradiation on the thermomechanical and morphological properties of chitosan obtained from prawn shell: evaluation of potential for irradiated chitosan as plant growth stimulator for Malabar spinach," Radiation Physics and Chemistry, vol. 82, no. 1, pp. 112-118, 2013.

[24] K. Yano, A. Usuki, A. Okada, T. Kurauchi, and O. Kamigaito, "Synthesis and properties of polyimide-clay hybrid," Journal of Polymer Science Part A: Polymer Chemistry, vol. 31, no. 10, pp. 2493-2498, 1993.

[25] S. F. Wang, L. Shen, Y. J. Tong et al., "Biopolymer chitosan/montmorillonite nanocomposites: preparation and characterization," Polymer Degradation and Stability, vol. 90, no. 1, pp. 123-131, 2005.

[26] E. Günister, D. Pestreli, C. H. Ünlü, O. Atici, and N. Güngör, "Synthesis and characterization of chitosan-MMT biocomposite systems," Carbohydrate Polymers, vol. 67, no. 3, pp. 358-365, 2007.

[27] M. G. F. Rodrigues, "Physical and catalytic characterization of smectites from Boa-Vista, Paraiba, Brazil," Ceramica, vol. 49, no. 311, pp. 146-150, 2003.

[28] J. Zhang, L. Wang, and A. Wang, "Preparation and properties of chitosan-g-poly(acrylic acid)/montmorillonite superabsorbent nanocomposite via in situ intercalative polymerization," Industrial and Engineering Chemistry Research, vol. 46, no. 8, pp. 2497-2502, 2007.

[29] Y. Xu, X. Ren, and M. A. Hanna, "Chitosan/clay nanocomposite film preparation and characterization," Journal of Applied Polymer Science, vol. 99, no. 4, pp. 1684-1691, 2006.

[30] R. J. Samuels, "Solid state characterization of the structure of chitosan films," Journal of Polymer Science: Polymer Physics Edition, vol. 19, no. 7, pp. 1081-1105, 1981.

[31] A. Toffey, G. Samaranayake, C. E. Frazier, and W. G. Glasser, "Chitin derivatives. I. Kinetics of the heat-induced conversion of chitosan to chitin," Journal of Applied Polymer Science, vol. 60, no. 1, pp. 75-85, 1996.

[32] K. Sakurai, T. Maegawa, and T. Takahashi, "Glass transition temperature of chitosan and miscibility of chitosan/poly $(\mathrm{N}$ vinyl pyrrolidone) blends," Polymer, vol. 41, no. 19, pp. 70517056, 2000.

[33] A. Casariego, B. W. S. Souza, M. A. Cerqueira et al., "Chitosan/ clay films' properties as affected by biopolymer and clay micro/ nanoparticles' concentrations," Food Hydrocolloids, vol. 23, no. 7, pp. 1895-1902, 2009.

[34] K. L. Shantha and D. R. K. Harding, "Synthesis and characterisation of chemically modified chitosan microspheres," Carbohydrate Polymers, vol. 48, no. 3, pp. 247-253, 2002. 

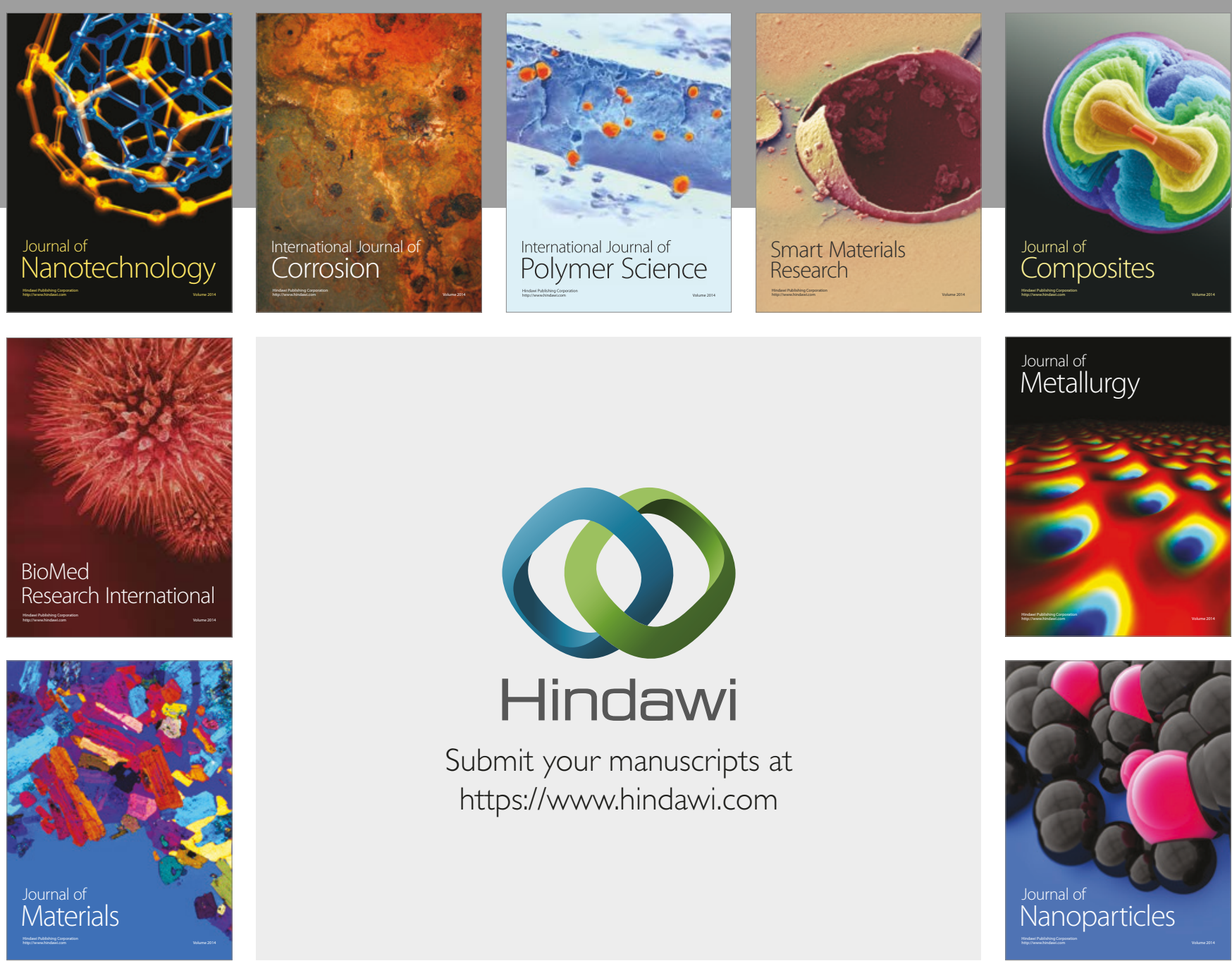

\section{Hindawi}

Submit your manuscripts at

https://www.hindawi.com
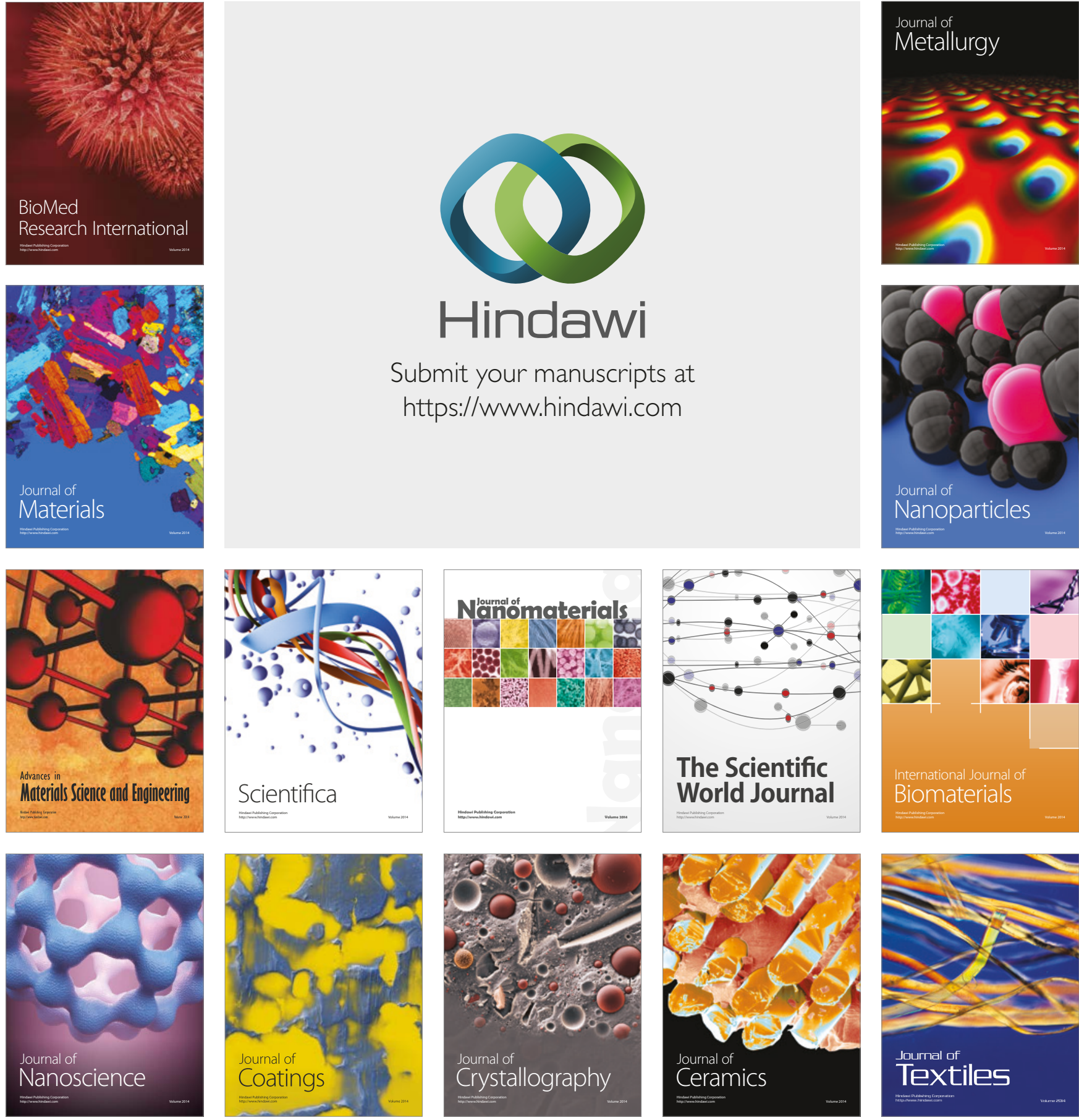

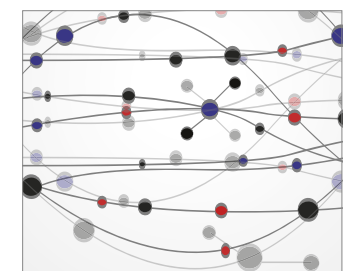

The Scientific World Journal
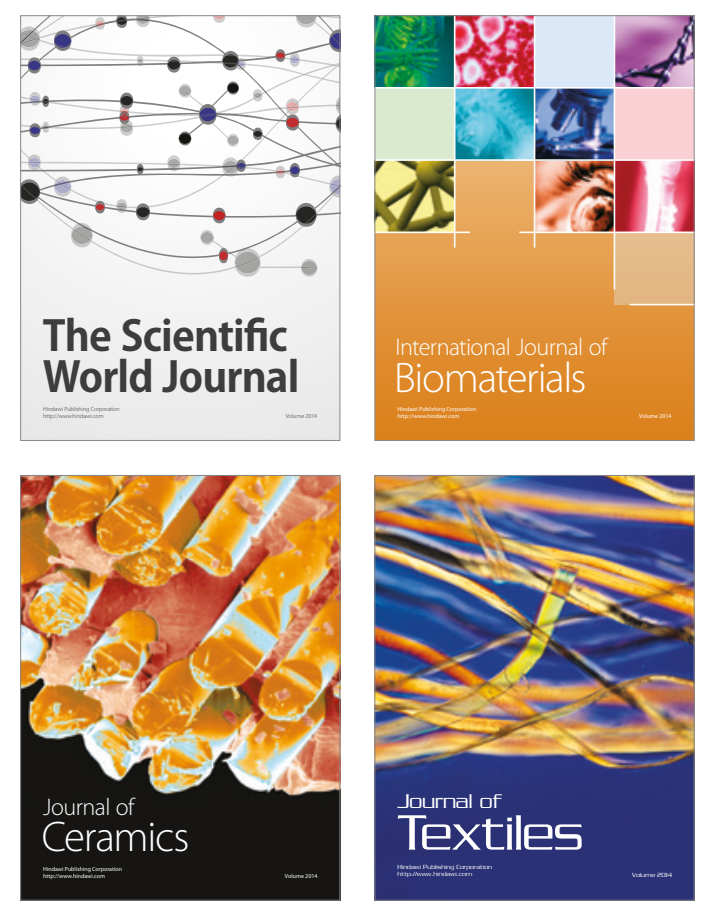